\title{
The role of social comparison and type of feedback on self-criticism in people with high levels of depressive symptoms
}

\author{
Andreea Amănălăchioaie ${ }^{1 *}$ \& Loredana R. Diaconu-Gherasim ${ }^{1}$ \\ ${ }^{I}$ Alexandru Ioan Cuza University of Iași, Romania \\ Received 02.12.2021; Received revised 30.09.2021; Accepted 15.10.2021 \\ Available online 30.12.2021
}

\begin{abstract}
This research explores the relation between social comparison and self-criticism on a group of participants with elevated rates of depressive symptoms. In addition, the study investigated whether the type of feedback could moderate the relation between social comparison and self-criticism. The sample included 36 psychology students in the first year $(\mathrm{N}=28$ women, $\mathrm{M}$ age $=24.6, \mathrm{SD}=4.66)$ with high depressive symptoms. Results show that higher rates of negative social comparison are correlated with higher levels of self-criticism. Participants that received negative feedback reported an increase level of self-criticism compared to those from positive feedback condition. The type of feedback moderated the relation between social comparison and self-criticism. Our findings are discussed from the perspective of their practical implications for young adults experiencing high levels of depressive symptoms.
\end{abstract}

Keywords: self-criticism, social comparison, feedback, depressive symptoms, moderation

Address of correspondence: Andreea Amănălăchioaie, Alexandru Ioan Cuza University of Iași. Address: 3 Toma Cozma St, 700554 Iași, Romania. E-mail: amanalachioaie.andreea@gmail.com

\section{Introduction}

Self-criticism is the harsh evaluation of one's own behavior and attributes and may be accompanied by a chronic fear of disapproval or self-incrimination (Powers, Zuroff \& Topciu, 2004; Powers, Koestner \& Zuroff, 2007). Previous research suggested that self-criticism is related to numerous psychiatric conditions, including high social anxiety, post-traumatic stress, depressive symptoms, or low self-efficacy (Dunkley, Zuroff \& Blankstein, 2003; Faranda \& Roberts, 2019; Gilbert, Durrant \& McEwan, 2006; Iancu, Bodner \& Ben-Zion, 2015). Self-criticism also may become a generalized self-concept that can have an unfavorable influence people's future actions and behaviors (Beck $\&$ Bredemeier, 2016). Given these effects, researchers have been concerned about social factors that could be linked to selfcriticism, such as social comparison (e.g., Gilbert, Baldwin, Irons, Baccus \& Palmer, 2006; Bäzner, Brömer, Hammelstein \& Meyer, 2006). However, in people with higher levels of depressive symptoms, few studies have concentrated on causes that may clarify the association between social comparison and selfcriticism. In order to advance the literature our research examined the relationship between social comparisons and self-criticism in participants with high depressive symptoms and if the type of feedback would explain as a moderator the relation between these constructs.

\section{Social comparison and self-criticism}

Social comparison theory postulates that people evaluate themselves by referring to an objective norm, and in its absence, they use other people to make social comparisons (Festinger, 1954). Therefore, social comparison requires self-evaluation in comparison to others to evaluate or integrate other elements of the self (Suls, Martin \& Wheeler, 2002). Social comparison refers to the ability to acquire and use knowledge about others to predict performance for a new task, according to the proxy model (Martin, 2013; Wheeler, Martin, \& Suls, 1997). Social comparison assumes comparison with others who are superior to us (upward social comparison) or lower from the perspective of comparison (downward social comparison) (Gerber, Wheeler \& Suls, 2017). Previous literature indicated that upward social comparison compared with downward social comparison may influence in positive way the people's selfperceptions (e.g., may lead to improved self-image or to increase self-evaluations of competence and motivation of people) (Campbell, Liao, Chuang, Zhou \& Dong, 2017; Lockwood \& Kunda, 1997; Mahler, Kulik, Gerrard, \& Gibbons, 2010). Further, when people compare themselves against a downward target, they can feel inferior and may experience negative affects, whereas the upward comparison may inspire reassurance, self-enhancement, and positive affects (Buunk \& Ybema, 1997).

From the perspective of the direction of comparison, social comparison could be described as a tendency to make comparisons with oneself and with others more positive (i.e., considering themselves as superior to the other) or negative (i.e., considering themself as inferior to the other) (Allan \& Gilbert, 1995). There are empirical findings which indicate that higher levels of positive social comparisons are related to positive self-examination (Alicke, Klotz, Breitenbecher, Yurak \& Vredenburg, 1995), whereas the negative social comparisons are linked to increased negative self-views and self-criticism (Allan \& Gilbert, 1995; Santor $\&$ Yazbeck, 2006). However, one study found that negative social comparisons may have some positive effects, by leading to self-improvement rather than negative self-beliefs (Wood, Michela \& Giordano, 2000).

According to the self-verification theory (Swann, Wenzlaff \& Tafarodi, 1992) depressed persons compared themselves with others more frequently than healthy persons and prefer interactions with those who perceive them as inferior and thus, may seek negative feedback. Previous literature shows that depressive people tend to make more negative social comparisons compared to healthy ones, who use positive social comparison to 
improve their mood (Bäzner et al., 2006; Gilbert, Baldwin et al., 2006; Thwaites \& Dagnan, 2004). Further, when depressed and non-depressive people compare with someone who is experiencing negative events, depressive people tend to feel worse than non-depressive ones (Gibbons \& Gerrard, 1989). It seems that people who have a negative affective state tend to avoid social comparisons with a person perceived as better, to avoid any negative effects they might experience. These findings may be explained by the tendency of depressive person to be more unhappy, and an unhappy person is less likely to attend and maintain a favorable information about the self (Sedikedes, 1992).

Few studies which evaluated the relation between social comparison (positive or negative) and self-criticism in people with high levels of depressive symptoms, indicate that negative social comparisons are associated with high rates of self-criticism in a sample of young adults with depressive symptoms (e.g., Abela, Webb, Wagner, Ho \& Adams, 2006; Faranda \& Roberts, 2019; Gilbert et al., 2001). Another research has shown that the people with depressive symptoms focus only in aspects that are congruent with their beliefs or cognition, even if they are negative, and thus their depressive symptoms are maintained (Woody et al., 2019). Thus, the presence of high depressive symptoms may be related with searching for negative stimuli for a long period of time.

The first aim of this research was to determine how social comparations are related to self-criticism. Considering previous literature (e.g., Abela et al., 2006; Gilbert et al., 2006) we predicted that negative social comparison of people with high levels of depressive symptoms would be linked to high levels of self-criticism.

\section{Effect of type of feedback on self-criticism}

The competency-based model of depression (Cole, 1991; Cole, Jacquez \& Maschman, 2001) states that people's development (e.g., social acceptance, behavior) and schemes about their own person are influence by the feedback they received predominantly during childhood. Thus, exposure to constantly negative feedback impacts the child's development by distorting the development of positive self-schemes (positive self-image and self-evaluation) and thus may determine the occurrence of depression (Cole et al., 2001). Further, exposure to predominately positive feedback helps children develop normal cognition and may lead to the development of positive self-schemes which can protect against depression.

Previous studies showed that the type of feedback plays a significant role in people's self-evaluations or self-efficacy or self-esteem (e.g., Ilies, De Pater \& Judge, 2007) or selfefficacy (Akkuzu, 2014; Ng \& Earl, 2008). A small number of studies have focused on the effect of feedback in other selfevaluations, such as self-criticism. The results show that the level of self-criticism can be different based on the type of feedback received on various tasks, like performance tasks or a memory test (Lueke \& Skeel, 2017; Stoeber, Hutchfield \& Wood, 2008). Specifically, the participants who received negative feedback tend to be more critical and decrease their performance, comparing with those who received positive feedback.

Persons with high rates of depressive symptoms reported an increase level of self-criticism after a personal failure (rejection) or actions (performance) comparing to the healthy ones (Deng et al. 2019; Kanfer \& Duerfeldt, 1968). The results were explained by those people with high levels of selfcriticism, who can experience rejection as a deep personal failure or feel that their status was attacked.

Because the type of feedback has an important role in activating one's negative view (i.e., self-criticism; Deng et al.
2019), this effect may appear in individuals with high levels of depressive symptoms. To deepen our understanding about the effects of the type of feedback on self-criticism on people with high rates of depressive symptoms; the level of depressive symptoms can be an important factor in way people react to the type of feedback they receive. The second aim of our study was to evaluate how types of feedback can impact on levels of selfcriticism on participants with high levels of depressive symptoms. Based on previous literature (e.g., Deng et al. 2019; Lueke \& Skeel, 2017) we expect that negative feedback will increase the level of self-criticism compared with the positive feedback condition.

\section{Type of feedback as a moderator for the relation between social comparison and self-criticism}

Previous studies had some mixed results regarding the effects social comparison have on self-criticism (e.g., Abela et al., 2006; Faranda \& Roberts, 2019; Wood et al., 2000). In this context, we evaluated whether the type of feedback may explain the relation between social comparison and self-criticism in people with high depressive symptoms as a moderator.

A very limited number of studies investigated the moderating function of feedback forms regarding the relationship between social comparison and self-criticism. As far as we know, one study has analyzed the correlation among the type of feedback, task performance and self-criticism in people with depressive symptoms; findings suggest that in negative feedback condition the association between performance and self-criticism is stronger (Lueke \& Skeel, 2017).

The third aim of our study was to determine whether type of feedback may moderate the relations between social comparison and self-criticism. Based on previous studies on the effects of feedback (Lueke \& Skeel, 2017) we expected that, in the negative feedback condition, the association between social comparison and self-criticism would have been stronger than in the positive feedback condition.

Previous results have concluded that subclinical depressive symptoms can be considered as part of a continuum of depression and would not vary significantly from clinical depression (Flett, Vredenburg \& Krames, 1997; Pettit, Hartley, Lewinsohn, Seeley \& Klein, 2013). Further, the risk factors for depressive symptoms are like those when it comes to the major depressive episode, and depression can be considered as part of a single continuous category (Liu, 2016). From this perspective, we consider that our study would bring information about the moderating role of the type of feedback in the relationship between social comparison and self-criticism in youth with high depression symptoms.

\section{Method}

\section{Participants}

Our sample initially included 189 first year psychology students $(N=120$ female, $M=23.3$ age, $S D=4.21)$. Participation was voluntary. The participants were recruited during an introductory course in psychology. They were not rewarded and did not receive any credits for their participation. In the first phase of the study the scale assessing the participants' depressive symptoms were filled in online, using the Google Forms platform. Only the participants $(\mathrm{N}=36)$ with a score higher than 21 at depression were included in this research.

\section{Measures}

Depressive symptoms. The Beck Depression Inventory (BDI -II; Beck, Steer, Ball \& Ranieri, 1996) measure the depressive symptoms experienced in the previous week among the participants. The Beck Inventory is a self-assessment scale of 
21 statements (e.g., I feel discouraged about the future) using a four-point scale from 0 (non-present symptom) to 3 (very serious symptom) and score by adding the ratings given to each statement. Total ratings above 21 suggest a mean-to-high level of depressive symptoms. The BDI has strong correlations with other scales measuring the depressive symptoms (Gary et al., 2018). In this study the Alpha Cronbach was .87.

Self-Criticism. To measure self-criticism, we use the Self-Critical subscale (9 items) from the scale of self-criticism and self-soothing forms (Gilbert Clarke, Hempel, Miles \& Irons, 2004). The instrument measures the participants' responses to a regress or disappointment (e.g., I am easily disappointed with myself). The participants rated the strength of their self-criticism in that moment using a four-point Likert scale from 0 (not my case at all) to 4 (very much my case). The total score was calculated by adding scores across all statements, a higher score suggesting a high level of selfcriticism. In this study the Alpha Cronbach was .76.

Social comparison. The Social Comparison Scale (11 items) was used to measure the social rank's expectations of self in comparison to others (Allan \& Gilbert, 1995). The participants made a global social comparison with the other people, on 11 bipolar items, from $1=\mathrm{I}$ feel inferior to others to $10=\mathrm{I}$ feel superior to others. The total score was determined by adding the scores across all statement, where a high total score imply positive social comparisons. The Alfa Cronbach in our research was 93.

Type of feedback. For feedback manipulation, we used an adapted scenario from Gilbert et al. (2006). The students were informed that they participated in research that evaluates how they react to different events. All the participants received a description of the same situation ("Imagine an activity for which you worked, and you had put in a lot of effort"), and then they were asked to image, either the result of the activity they carried out was negative (negative feedback scenario) or to imagine that the result of the activity was positive (positive feedback scenario). Then, participants were randomly distributed to experimental conditions (positive versus negative feedback). They had the task to think about how they felt, their effort to solve the task and the feeling of being appreciated (for a positive feedback scenario) or feeling of being unappreciated/rejected (negative feedback scenario). All the participants had 30 seconds to think about a response.

\section{Procedure}

Initially, the participants filled out the social comparison scale, then they read the scenario according to their experimental condition and filled out the self-criticism scale. Finally, for the debriefing, the students received a message where the purpose of the study was explained, and they were told that the feedback received had no relevance to their real abilities (to counteract possible negative self-assessments).

\section{Results}

\section{Preliminary analyses}

Initially, we verify the normality of the data distribution. The results of the Shapiro-Wilk test show that data did not have normal distribution (social comparison $=.887, p=.001$; self-criticism $=.868 ; p=.002$; feedback $=.638, p=.000)$. We normalized the data using the A Two-Step Transformation to Normality method (Templeton \& Burney, 2017). Also, we analyzed the relations between self-criticism and age. Our results shown that was no association between the participants' age and self-criticism, $r=.04, p=.78$. Further, the $t$ test shown that was no gender differences in selfcriticism, $t(34)=.74, p=.46$.
Associations between social comparison and self-criticism

The zero order-correlations indicate a negative significant association between self-criticism and positive social comparison, $r=-.865, p<.01$. The participants with high levels of depressive symptoms who reported more positive social comparison reported lower levels of self-criticism.

Effect of type of feedback effect on self-criticism

The $t$ test for independent samples indicated a significant effect of type of feedback on self-criticism $t(34)=19.85 ; p<$ .001 . The participants with high levels of depressive symptoms from the negative feedback condition $(M=74.38, S D=6.09)$ were more self-critical than those who from positive feedback condition $(M=38.22, S D=4.74)$.

The moderating role of feedback on the relation between social comparison and self-criticism

To test our third hypothesis that type of feedback moderates the relation between social comparison and selfcriticism, we conducted a hierarchical multiple regression analysis via Process (Hayes, 2013). The social comparison was included in first block, type of feedback in the second block, and then we added the interaction term between social comparison and feedback. We centered the two variables before computing the interaction term. The findings show that all variables account for a significant amount of self-criticism variation, $\Delta R^{2}=.94, F$ $(2,35)=239.925, p<.001)$. Social comparison $\beta=-.865, p<$ .001 and type of feedback $\beta=-1.310, p<.001$ significantly predict the level of self-criticism. Further, the results indicate a significant interaction between social comparison and type of feedback on self-criticism, $\beta=-1.844, p<.001$ (see Table 1). Following Dawson's (2014) method, we examined the nature of the significant interaction term (see Figure 1).

Table 1. Means, standard deviation and correlations between self-criticism, social comparison, and feedback type

\begin{tabular}{lccccc}
\hline Variable & $M$ & $S D$ & 1. & 2. & 3. \\
\hline $\begin{array}{c}\text { 1. Self- } \\
\text { criticism }\end{array}$ & 56.30 & 19.11 & - & $-.865^{* *}$ & $-.959^{* *}$ \\
$\begin{array}{l}\text { 2. Social } \\
\text { comparison }\end{array}$ & 53.75 & 22.11 & & - & $.944^{* *}$ \\
$\begin{array}{l}\text { 3. Feedback } \\
\text { type }\end{array}$ & & & & & - \\
\hline
\end{tabular}

\section{Discussion}

This study is aimed at examining the role of social comparison on self-criticism among young adults with high levels of depressive symptoms. Our second aim was to determine whether the type of feedback is a potential moderator of the relation between social comparison and self-criticism.

The results show a negative relation between social comparison and self-criticism in individuals with high depressive symptoms, and our results are in line with previous studies (Abela et al., 2006; Faranda \& Roberts, 2019). Our research advances the literature showing that a high level of positive social comparison is related with a decrease of selfcriticism on a sample of young adults with depressive symptoms. Future studies should also evaluate if positive social comparison and self-criticism can decrease long-term depressive symptoms.

Our results suggest that the participants reported higher levels of self-criticism when they received negative feedback compared to those who received positive feedback. These results are in line with literature that has shown that negative feedback influences the level of self-criticism (Deng et al. 2019; Lueke \& Skeel, 2017). 


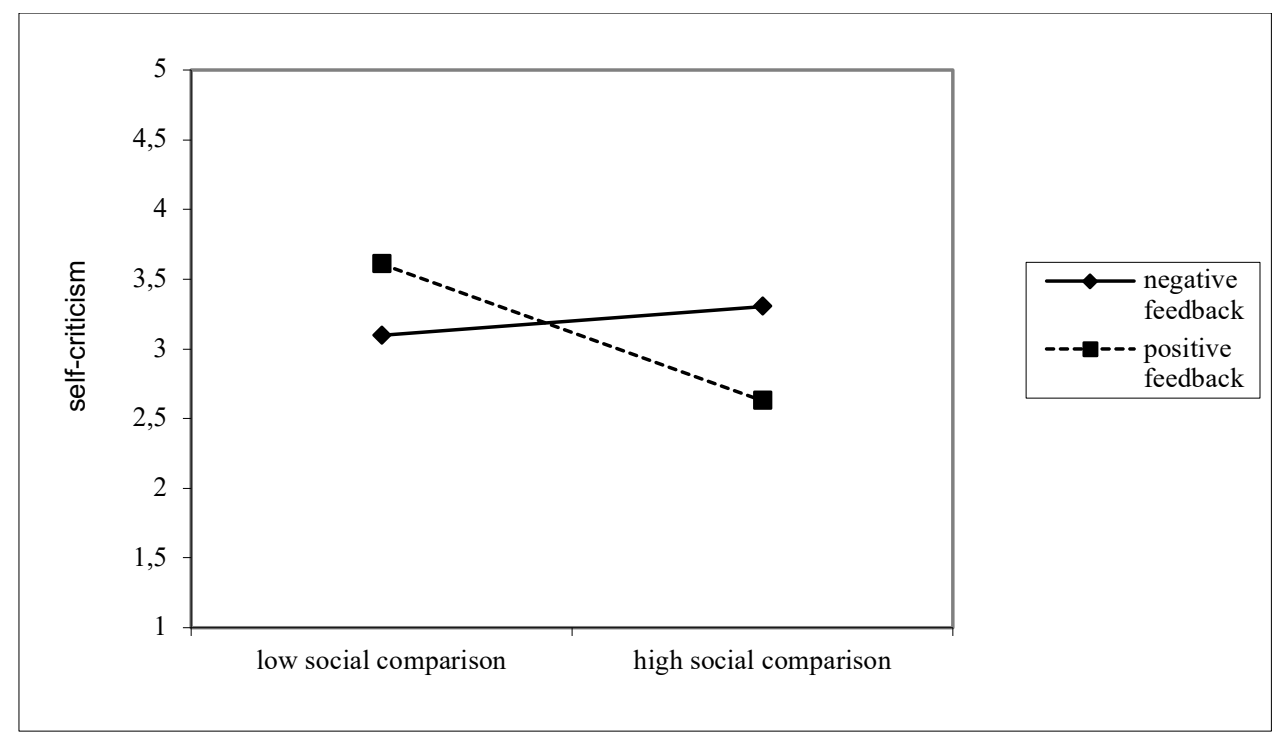

Figure 1. The moderation role of the type of feedback on the relation between social comparison and self-criticism

These findings are in line with Swann's self-verification theory (1992) emphasizing that people who experience self-criticism will confirm their negative self-opinion through feedback (i.e., negative). Our research brings additional support for the importance of positive feedback when it comes to reducing selfcriticism in the participants with higher levels of depressive symptoms (Gilbert, Baldwin el al., 2006). Future research should evaluate whether the positive feedback provided can help in reducing the depression symptoms, beyond selfcriticism.

Furthermore, the type of feedback moderates the relation between social comparison and self-criticism. Our results showed that for people with higher levels of depressive symptoms the link between social comparison and self-criticism is stronger in the case of negative feedback than in the case of positive feedback. It seems that the negative feedback received by people scoring high on depression is detrimental for their mental health because their higher level of self-criticism also activates more negative social comparison leading to a vicious cycle. In the positive feedback condition, the relation is weaker, meaning that positive feedback acts as buffer that reduces the link between social comparison and self-criticism. With other words, positive feedback received by people scoring high on depression may be beneficial for their mental health because negative social comparisons do not necessary bring more selfcriticism and vice versa. These findings are in line with selfverification theory (Swann et al., 1992) arguing that depressed persons tend to make negative comparation and are more likely to maintain more unfavorable information about the self Positive feedback may evoke a positive and warmth perception about themselves which might lead to activating a kind and warm attitude toward self, as opposed to self-criticism judgments (Gilbert, Durrant et al., 2006). Our findings suggest that positive feedback is important the weakening the connection between negative social comparison and selfcriticism, two self-evaluations relevant for the occurrence and maintenance of depressive symptoms.

Our study presents several limitations. First, we did not measure the level of depressive symptoms after the experimental feedback. Thus, we are not sure whether the levels of depressive symptoms temporally changed due to the experimental manipulation of feedback. Future studies should evaluate whether under the influence of positive feedback (which activates self-indulgence) depression diminishes. Secondly, we evaluated only the participants with high levels of depressive symptoms and a small sample, and we cannot generalize the results on clinical samples. Further, future studies should investigate the relation among our constructs on samples of participants with various subtypes of depression and on a larger sample for a better understanding of the relations among constructs. Third, we rely on self-reported data and thus, desirable answers could have appeared. Future studies should focus on collecting information through other objective methods (e.g., interview). Finally, our research is crosssectional, and longitudinal studies may provide more information regarding the relations among type of feedback, social comparison and self-criticism over time.

Our study has several practical implications. First, practitioners should focus more on helping young people with depressive symptoms by providing them with more strategies to counteract the effects of negative feedback to help in reducing their level of self-criticism. Another aspect is that practitioners can help by providing more positive feedback to persons with high levels of depressive symptoms. Furthermore, since negative social comparisons used by people with high levels of depressive symptoms are linked to self-criticism, it is important that young adults with high levels of depressive symptoms receive education about mechanisms and the effects of negative social comparison, as well as orienting them towards more positive social comparisons.

Our study examined the relation between social comparison and self-criticism, and if type of feedback moderates this link. Our results indicate that positive social comparison is related with a lower level of self-criticism. The participants registered an increased level of self-criticism when they received negative feedback compared with those from positive feedback condition. Moreover, the association between social comparison and self-criticism is moderated by type of feedback on a sample of participants with high levels of depressive symptoms. Future research should evaluate whether positive feedback can lead to a decrease of depressive symptoms over time. Also, future studies should verify if providing positive feedback and encouraging positive social comparisons can be a strategy for persons with high levels of depressive symptoms.

\section{References}

Abela, J. R., Webb, C. A., Wagner, C., Ho, M. H. R., \& Adams, P. (2006). The role of self-criticism, dependency, and hassles in the course of depressive illness: A multiwave longitudinal study. Personality and Social Psychology Bulletin, 32(3), 328338. https://doi.org/10.1177/0146167205280911

Akkuzu, N. (2014). The Role of Different Types of Feedback in the Reciprocal Interaction of Teaching Performance and Selfefficacy Belief. Australian Journal of Teacher Education, 39(3), 37-67. http://dx.doi.org/10.14221/ajte.2014v39n3.3 
Self-criticism and depressive symptoms

Allan, S., \& Gilbert, P. (1995). A social comparison scale: Psychometric properties and relationship to psychopathology.

Personality and Individual Differences, 19(3), 293-299. https://doi.org/10.1016/0191-8869(95)00086-L

Alicke, M. D., Klotz, M. L., Breitenbecher, D. L., Yurak, T. J., \& Vredenburg, D. S. (1995). Personal contact, individuation, and the better-than-average effect. Journal of Personality and Social Psychology, 68(5),

804-825. https://doi.org/10.1037/0022-3514.68.5.804

Bäzner, E., Brömer, P., Hammelstein, P., \& Meyer, T. D. (2006). Current and former depression and their relationship to the effects of social comparison processes. Results of an internet based study. Journal of Affective Disorders, 93(1-3), 97-103. https://doi.org/10.1016/j.jad.2006.02.017

Beck, A. T., \& Bredemeier, K. (2016). A Unified Model of Depression. Clinical Psychological Science, 4(4), 596-619. https://doi.org/10.1177/2167702616628523

Beck, A. T., Steer, R. A., Ball, R., \& Ranieri, W. F. (1996). Comparison of Beck Depression Inventories-IA and-II in psychiatric outpatients. Journal of Personality Assessment, 67(3),

588-597. https://doi.org/10.1207/s15327752jpa6703 13

Buunk, B. P., \& Ybema, J. F. (1997). Social comparisons and occupational stress: The identification-contrast model. In B. Buunk \& F. X. Gibbons (Eds.), Health, Coping, and WellBeing: Perspectives From Social Comparison Theory. (pp. 359-388). Mahwah, NJ Lawrence Erlbaum Associates.

Campbell, E. M., Liao, H., Chuang, A., Zhou, J., \& Dong, Y. (2017). Hot shots and cool reception? An expanded view of social consequences for high performers. Journal of Applied Psychology, 102(5), 866. https://doi.org/10.1037/apl0000183

Cole, D. A., Jacquez, F. M., \& Maschman, T. L. (2001). Social origins of depressive cognitions: A longitudinal study of selfperceived competence in children. Cognitive Therapy and Research, 25(4),

377-395. https://doi.org/10.1023/A:1005582419077

Cole, D. A. (1991). Preliminary support for a competency-based model of depression in children. Journal of Abnormal Psychology, 100(2), 181-190. https://doi.org/10.1037/0021843X.100.2.181

Dawson, J. F. (2014). Moderation in management research: What, why, when and how. Journal of Business and Psychology, 29, 1-19. https://doi.org/10.1007/s10869-013-9308-7

Deng, Y., Wang, S., Leng, L., Chen, H., Yang, T., \& Liu, X. (2019). Pleasing or withdrawing: Differences between dependent and self-critical depression in psychosocial functioning following rejection. Personality and Individual Differences, 140, 4-9. https://doi.org/10.1016/j.paid.2018.02.037

Dunkley, D. M., Zuroff, D. C., \& Blankstein, K. R. (2003). Selfcritical perfectionism and daily affect: Dispositional and situational influences on stress and coping. Journal of Personality and Social Psychology,84(1), 234-252. https://doi.org/10.1037/0022-3514.84.1.234

Faranda, M., \& Roberts, L. D. (2019). Social comparisons on Facebook and offline: The relationship to depressive symptoms. Personality and Individual Differences, 141, 13-17. https://doi.org/10.1016/j.paid.2018.12.012

Festinger, L. (1954). A theory of social comparison processes. Human Relations, 7(2), 117-140. https://doi.org/10.1177/001872675400700202

Flett, G. L., Vredenburg, K., \& Krames, L. (1997). The continuity of depression in clinical and nonclinical samples. Psychological Bulletin, 121(3), 395-416. https://doi.org/10.1037/0033-2909.121.3.395

Gary, F. A., Yarandi, H., Evans, E., Still, C., Mickels, P., Hassan, M., ... \& Conic, R. (2018). Beck Depression Inventory-II: Factor Analyses with Three Groups of Midlife Women of African Descent in the Midwest, the South, and the US Virgin Islands. Issues in Mental Health Nursing, 39(3), 233-243. https://doi.org/10.1080/01612840.2017.1373175

Gerber, J. P., Wheeler, L., \& Suls, J. (2017). A Social Comparison Theory Meta- Analysis 60+ Years On. Psychological Bulletin. Advance online https://doi.org/10.1037/bul0000127

Gibbons, F. X., \& Gerrard, M. (1989). Effects of upward and downward social comparison on mood states. Journal of
Social and Clinical Psychology, 8(1),

14-31. https://doi.org/10.1521/jscp.1989.8.1.14

Gilbert, P., Durrant, R., \& McEwan, K. (2006). Investigating relationships between perfectionism, forms and functions of self-criticism, and sensitivity to put-down. Personality and Individual Differences, 41(7), https://doi.org/10.1016/i.paid.2006.05.004

Gilbert, P., Baldwin, M. W., Irons, C., Baccus, J. R., \& Palmer, M. (2006). Self-Criticism and Self-Warmth: An Imagery Study Exploring Their Relation to Depression. Journal of Cognitive Psychotherapy, $20(2)$ 183-200. https://doi.org/10.1891/jcop.20.2.183

Gilbert, P., Clarke, M., Hempel, S., Miles, J. N. V. \& Irons, C. (2004). Criticizing and reassuring oneself: An exploration of forms, styles and reasons in female students. British Journal of Clinical Psychology, 43, 31-50. https://doi.org/10.1348/014466504772812959

Gilbert, P., Birchwood, M., Gilbert, J., Trower, P., Hay, J., Murray, B., ... \& Miles, J. N. V. (2001). An exploration of evolved mental mechanisms for dominant and subordinate behaviour in relation to auditory hallucinations in schizophrenia and critical thoughts in depression. Psychological Medicine, 31(6), 11171127. https://doi.org/10.1017/S0033291701004093

Hayes, A. F. (2013). Introduction to mediation, moderation, and conditional process analysis: Methodology in the Social Sciences. Kindle Edition.

Iancu, I., Bodner, E., \& Ben-Zion, I. Z. (2015). Self esteem, dependency, self-efficacy and self-criticism in social anxiety disorder. Comprehensive Psychiatry, 58, 165-171. https://doi.org/10.1016/j.comppsych.2014.11.018

Ilies, R., De Pater, I. E., \& Judge, T. (2007). Differential affective reactions to negative and positive feedback, and the role of selfesteem. Journal of Managerial Psychology, 22 (6), 590-609. https://doi.org/10.1108/02683940710778459

Irons, C., Gilbert, P., Baldwin, M.W., Baccus, J. R., Palmer, M. (2006). Parental recall, attachment relating and self-attacking/ self-reassurance: Their relationship with depression. British Journal of Clinical Psychology, 45, 297-308. https://doi.org/10.1348/014466505X68230

Kanfer, F. H., \& Duerfeldt, P. H. (1968). Comparison of self-reward and self-criticism as a function of types of prior external reinforcement. Journal of Personality and Social Psychology, 8(31), 261-268. https://doi.org/10.1037/h0025508

Liu, R. T. (2016). Taxometric evidence of a dimensional latent structure for depression in an epidemiological sample of children and adolescents. Psychological Medicine, 46(6), 1265-1275. https://doi.org/10.1017/S0033291715002792

Lockwood, P., \& Kunda, Z. (1997). Superstars and me: Predicting the impact of role models on the self. Journal of Personality and Social Psychology, 73, 91-103. https://doi.org/10.1037/0022-3514.73.1.91

Lueke, N., \& Skeel, R. (2017). The effect of self-criticism on working memory in females following success and failure. Personality and Individual Differences, 111, 318-323. https://doi.org/10.1016/j.paid.2017.02.035

Mahler, H. I., Kulik, J. A., Gerrard, M., \& Gibbons, F. X. (2010). Effects of upward and downward social comparison information on the efficacy of an appearance-based sun protection intervention: A randomized, controlled experiment. Journal of Behavioral Medicine, 33(6), 496-507. https://doi.org/10.1007/s10865-010-9279-3

Martin, R. (2013). " Can I do X?": Using the proxy comparison model to predict performance. In Suls, J., \& Wheeler, L. (Eds.). Handbook of social comparison: Theory and research. (pp. 67-80). Springer Science \& Business Media. New York

Ng, J. R., \& Earl, J. K. (2008). Accuracy in Self-Assessment: The Role of Ability, Feedback, Self-Efficacy and Goal Orientation. Australian Journal of Career Development, 17(3), 39-50. https://doi.org/10.1177/103841620801700307

Pettit, J. W., Hartley, C., Lewinsohn, P. M., Seeley, J. R., \& Klein, D. N. (2013). Is liability to recurrent major depressive disorder present before first episode onset in adolescence or acquired after the initial episode? Journal of Abnormal Psychology, 122(2), 353-358. https://doi.org/10.1037/a0032655

Powers, T. A., Koestner, R., \& Zuroff, D. C. (2007). Self-criticism, goal motivation, and goal progress. Journal of Social and $\begin{array}{lr}\text { Clinical Psychology, 26(7), } & \text { 826-840. }\end{array}$ 
https://doi.org/10.1521/jscp.2007.26.7.826

Powers, T., Zuroff, D. C. \& Topciu, R. A. (2004). Convert and overt expressions of self-criticism and perfectionism and their relation to depression", European Journal of Personality, 18, 61-72. https://doi.org/10.1002/per.499

Santor, D. A., \& Yazbek, A. A. (2006). Soliciting unfavourable social comparison: Effects of self-criticism. Personality and Individual Differences, 40(3), https://doi.org/10.1016/j.paid.2005.06.029

Sedikedes, C. (1992). Attentional effects on mood are moderated by chronic self-conception valence. Personality and Social Psychology Bulletin,
https://doi.org/10.1177/0146167292185008

Suls, J., Martin, R., \& Wheeler, L. (2002). Social comparison: Why, with whom, and with what effect? Current Directions in Psychological $\quad$ Science, 11(5), 159-163. https://doi.org/10.1111/1467-8721.00191

Stoeber, J., Hutchfield, J., \& Wood, K. V. (2008). Perfectionism, self-efficacy, and aspiration level: Differential effects of perfectionistic striving and self-criticism after success and failure. Personality and Individual Differences, 45(4), 323327. https://doi.org/10.1016/j.paid.2008.04.021

Swann, W. B., Wenzlaff, R. M., \&Tafarodi, R. W. (1992). Depression and the search for negative evaluations: More evidence of the role of self-verification strivings. Journal of
Abnormal Psychology, 101(2),

314-

Templeton, G. F., \& Burney, L. L. (2017). Using a two-step transfor Thwaites, R., \& Dagnan, D. (2004). Moderating variables in the relationship between social comparison and depression: An evolutionary perspective. Psychology and Psychotherapy: Theory, Research and Practice, 77(3), 309323. https://doi.org/10.1348/1476083041839376

Wheeler, L., Martin, R., \& Suls, J. (1997). The Proxy social comparison model for self-assessment of ability. Personality and Social Psychology Review, 1, 54-61. https://doi.org/10.1207/s15327957pspr0101 4

Wood, J. V., Michela, J. L., \& Giordano, C. (2000). Downward comparison in everyday life: Reconciling self-enhancement models with the mood-cognition priming model. Journal of Personality and Social Psychology, 79(4), 563-579. https://doi.org/10.1037/0022-3514.79.4.563

Woody, M. L., Rosen, D., Allen, K. B., Price, R. B., Hutchinson, E., Amole, M. C., \& Silk, J. S. (2019). Looking for the negative: Depressive symptoms in adolescent girls are associated with sustained attention to a potentially critical judge during in vivo social evaluation. Journal of Experimental Child Psychology, 179,

90-102. 